\title{
The Paradise Problem: Painted Experience
}

\author{
Angela Meyer \\ James Cook University, Cairns \\ \& \\ Stephen Naylor \\ James Cook University, Singapore
}

\begin{abstract}
This research focuses on a sample group of painters who have worked in the North Queensland wet tropics where they have explored tropical imagery within western traditions. Despite some acknowledgement of the Pacific by Smith (1960) and some engagement by established southern artists in fleeting visits to the North; there has been little research into contributions of the contemporary painters working within the wet tropical regions of northern Australia. This research challenges some of the late 19th century and early 20th century filters established by the painters Gauguin, Matisse and Henri Rousseau in finding a tropical paradise, through the presentation of data collected from the selection of artists working in the tropics, teasing out the contradictions within the work of mainstream art historians.
\end{abstract}

\begin{abstract}
$\mathrm{A}$ ustralian art is predicated on a European paradigm in terms of its physiological applications and philosophical dichotomies. Australian art follows the European objectives of asserting a political voice to unveil oppression or request change, allow creative expression, deliver a pathway of communication, make concrete the inexplicable and serve as social glue that connects culture to geography (Berger-Schmitt, 2000). Our history is written largely through a European gaze whereby the Antipodes can never be more than an imitation of the English ideology and will always be imagined through a narrowly defined lens. The early work by Australian art historians such as Bernard Smith and Robert Hughes generated a foundation on which to classify and compartmentalise the practice of Australian painting from colonial times through to the contemporary, within a conventional range of Western norms.
\end{abstract}

The intent of this project was to produce a body of work around the subject Tropical Paradise and its light and shadows. The work aimed to synthesise concepts of a tropical lived experience collected from research in existing literature and from interviews with artists who paint and live in the North Queensland tropics. The intent was to produce research that contributes to contemporary painting practice within tropical space, dealing with the implications of tropical space as a measurable experiment. This is understood through Aristotle's notion of the Torrid zone that encompasses the tropics and a contemporary engagement with tropical space through lived experience.

Defining what is tropical can be achieved through the impact of the environment on the painting practices in Far North Queensland, revealed as a comparison between tropical and temperate climates. In a snapshot view of 'the tropics' in painting in this region, we are largely drawn to the paintings of Ray Crooke that capture the physical aesthetics of tropical space. In his work is portrayed the binary aspects of tropical paradise with the bright 
illuminated colour and the pensive atmosphere in his brooding shadows. His work is a departure from earlier depictions in western culture by painters such as Gauguin, Matisse and Rousseau. The influence of the post-impressionist painters deposited a residue of contradictions. This research defines the recurrent quality found in the aesthetics and distinct sensibility of tropical paintings of Far North Queensland.

The awareness of self in space has been examined from a historical perspective in terms of human movement across geography and the Australian position within that. British empiricism took seriously "problematic Idealism" through self-referential understanding. The construction of interpretation and the deconstruction of understanding to reveal ideas of truth as explained through western metaphysics (Macann, 1996) leads to an outcome of perceptions as explanatory descriptions from the artists interviewed in the case studies who were able to articulate their sensory reactions to the tropics as a particular space or through the lens of paradise. Results expose the empirical or individual mind and the transcendental or universal mind to reveal essentially a narrative story in Kant's cornopean model that "insisted upon a dualism between understanding and sensibility, so that the transcendental subject is the source not of only the form but the matter of experience" (Beiser, 2009, p. 1). German idealism went further as explained by Frederick Beiser in this ideological struggle as a "progressive triumph of subjectivism, in the gradual expansion of the circle of consciousness" (Beiser, 2009, pp. 2-3). Gradually the tropics are revealed as a particular kind of space. For Mark Conner editor of Two Centuries of Australian poetry 1988 it is the mangoes and bougainvillaeas in contrast to the lilac bushes and apples trees that distinguish the tropic and temperate zones.

These reinterpretations mark thought processes, engaged in new space and broadening selfawareness both as a product of methodical experiment through interviewing artists about tropical space and as an ongoing growth and revision of knowledge. This cyclical notion is expressed as "What is really moving about Hegel's view of history is the idea that nothing is ever really lost. Ideas that we move on from continue to have an impact and a presence in the view of the world which we go on to adopt" (Armstrong, 2004, p. 151). The human element of choice as subject matter is expressed by Socrates beginning with the role of the author as creative poet "The rhapsode like yourself and the actor are intermediate links, and the poet is the first of them" (Socrates) (Hofstadter, 1976, p. 56).

The canvases produced reflect on these ideas and look for a connection with the aesthetic and lived experience of the wet tropics region of North Eastern Australia. The portrait of Zane Saunders considers the convention of portraiture as a framework for contemporary conversation. This portrait reflects on Ray Crooke's depiction of Father Boggo Pilot in Island Priest 1958. Crooke's portrait is in the traditional ecclesiastical style that references the missionary presence in the Torres Straits and the European culture imposed therein. Crooke wanted to bridge the gulf between the Christian position and Island values (Smith, 1997). Borrowing from the post-expressionist styles of the early nineteenth century revisits the objectives of the Neue Sachlichkeit which "absorbed the lessons that the arts of the indigenous people had to teach while rejecting the primitivistic ideology that had been imposed upon it" (Smith, 1998, p. 143). This portrait reflects a personal experience around discussion and familiarity. 


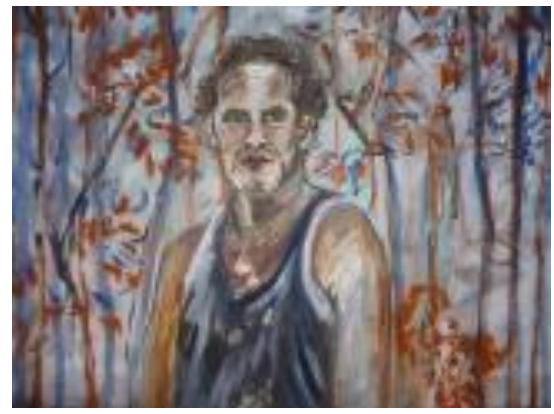

Figure 1: Theology student: Portrait of Zane Saunders, 2013.

Paradise may have been left out of the lexicon of the inner city but according to Christopher Allen the characteristic of the Postmodernist style is the "one which obviously responded to and embraced the new historical conditions in which Australia is as involved as the rest of the world" (Allen, 1997). Aesthetically urban Australian artists took their visual cues from New York, Italy and France, rather than consider "culture" that is found on our extraordinary continent. Perhaps the root of urban radical thought lay in nature in its rawest form, that of shapes, which coalesced with the earlier historical exploration and observations of Charles Darwin and Alfred Wallace in their studies of nature in the tropical regions. For centuries not only religion and philosophy have considered the notion of Paradise, the Garden of Eden in the wet tropics landscape or the whole story of creation in a very earthly manner. Whether the art of the Tropics will achieve Kant's proposition that true virtue can be raised by an appreciation and understanding of the beautiful and the sublime, and thus enact the principles of humanity's beauty and dignity means that the tropics is not just an escape as suggested by Gavin Wilson, or inspiration for botanists and explorers, but a valid space unto itself.

Understanding tropical local space is a personal investigation on one level and a conversation that participates in a far reaching discourse. The personal experience of painting and interacting with the world within a human capacity is not only an artistic premise it also recognizes an ingrained spiritual connection to community and place. The human interaction is expressed through a play of imagery that describes experience. The mark making and symbolism of foliage is an expression of self in the painting while another layer operates as visual language understood art by other artists and critics who can contextualize the processes and meanings. In this way painting is communicating to other artists who understand the language of the painting medium. The artist statement of "Tropical Paradise: its light and its shadows" asks the audience to consider what is being communicated in the works. This statement proposed as a goal also acts as a directive to keep referring back to see the focus of study in terms of the purpose and reason for the creation of the paintings. In conversation with Zane Saunders (personal communication, 2013) he described the exercise of purposefully using dark colours as a process of enrichment is the paintings that dwell on the shadows. He discussed black as colour which isn't really there, but does exist as tone. He considered darkness as a strategy to achieve depth. This depth also uses the technique of narrative as a story telling device that reaches back to the basics or roots, as universal principles that occur in ancient mythologies.

The Torrid Zone, originally defined by Aristotle, suggested that the tropics were a site of degradation which was largely uninhabitable. Following the early explorations of James Cook as discussed by Bernard Smith (1960), as well as accounts of the naturalists and explorers Alfred Wallace, Charles Darwin and Alexander von Humboldt we come to the 
reality of the tropics as a lived, inhabited and celebrated space. Contemporary scholars Nancy Stepan (2001) and Felix Driver (2005) enter a discussion that investigates how the tropics gain position in western thought. The philosophical and psychological understanding of internal imagined space through sociologist Edward Said's (1978) term Orientalism reflects on how the tropics have been imagined as "other" in the west.

Britain's objectives for exploration underscore how interest in tropical nature in Australia has emerged. In 1768 Britain founded the Royal Academy (Smith, 1960) that aimed to promote an understanding of nature, based on neo-classical thought that was underpinned by the French theories of de Chambray (1650) and de Piles (1669). It was in this same year that the Royal Society engaged James Cook to sail the South Seas to record the transit of Venus. It was the illustrations of Joseph Banks on this voyage that were to inspire Alexander von Humboldt. Smith continues "Now the opening of the Pacific provided a new world for the philosophers of nature" (Smith, 1985, p. 1). An inspired mythology of tropical arcadia sprang forth to inspire a European audience with a patchwork of impressions and artefacts, meanwhile presenting opportunities of discovery for the explorers.

Australian curators Ross Searle(1991), Gavin Wilson (1998) and John Millington (1987) traverse the immediacy of tropical space in exhibitions of paintings that begin to define a tropical North Queensland awareness. The Paradise Problem utilises a series of case studies of painters of the wet tropics region of North Queensland. To reflect "the world of human experience" (Cohen, 1994, p. 36) a mixed method approach employed questionnaires and interviews to generate feedback from participant artists: Ray Crooke, Claudine Marzik, Amanda Feher, Laurine Field, Ian Smith, James Baines, Claire Souter, Helen Wiltshire and Margaret Olley. The visual narratives and painting practices of these painters are located within a discourse that examine the tropics as a real world contemporary experience and seeks to synthesise an emotional reaction to life in the tropics that represent physical spiritual journeys through light and shadow.

The timeless qualities of tropical landscape representing things like abundant nature, minimal variations in day and night temperatures, an absence of twilight at dusk and dawn, consistent rainfall, high humidity, bright daylight and lush foliage caught the early imagination of botanists and explorers who set about understanding the intrinsic qualities of the cornucopia in terms of a paradise (Von Humboldt, 1849 ). In this sense tropical nature offers the transcendental position as an idealised space of paradise, understood as the Garden of Eden. The ancient Greeks had no such word for paradise, and it wasn't until Xenophon (Ashton, 2001) introduced the adaption from the Persian word pairadeios, meaning a garden park or walled enclosure, to paradeisos into the Greek language in the fourth century B.C.E. that the idea was conceived. We may also consider the ancient indigenous beliefs native to the people of Australian continent. Aboriginal beliefs do not identify with the western notion of paradise as a lost golden age beyond the reach of mortals, or a walled garden of Eden (Ashton, 2001). Rather they identify with the natural world through their relationship with ancestral beings which access the power of the Dreamtime.

The quest for Paradise became dynamic in the European art movements of the postimpressionists who were looking for symbolic depth and vigour(Foster, 2011). Gauguin, Rousseau and Matisse were seeking the inspiration that paradise suggested, and for them located within tropical geography, whether physically or via the construct of their imagination. The imagined paradise they longed for may have been the permanent contentment, eternal bliss or rejuvenating qualities described by Herschel (1830) who aimed 
"to promote the active and dynamic sense of nature" (Ruskin, 2004, p. 115). However human geography traverses tropical space, the concept of lived experience in the tropics is different from a tourist visit to the tropics. This fascination originated with naturalists and explores such as Charles Darwin and Alfred Wallace who discovered tropical exotica from their journeys to tropical regions including South America and Asia. After the specimens from their explorations were taken back to Europe the tropics became an imagined space linked to these objects of discovery. The tropics became represented as a desirable superabundant and fertile space enhanced by extraordinary plant life like giant waterlilies, orchids, bromeliads and varied fauna. However other attributes such as disease, danger, the bizarre and overtly sexual, also suggested that the tropics was a denigrated space of "fatal excess" (Stepan, 2001).

To unpack the stereotypes around regional North Queensland culture a prism is required to re-evaluate it. The exotic paradigm in Orientalism allows such a perspective, if we are to truly see the impact of western thought in this culture. Edward Said offers that to "understand Europe properly meant understanding the objective relatives between Europe and its own previously unreachable temporal and cultural frontiers" (Said, 2003, p. 120). He calls Orientalism a late $18^{\text {th }}$ century construct, "a way of coming to terms with the Orient that is based on the Orient's special place in European western experience" (Said, 2003, p. 1). This notion he argues is a deep and recurring aspect of "other" that gave European culture an identity by contrasting itself to the Orient as a surrogate or underground self. The language Said uses to create this contrast are: "its strangeness, its difference, its exotic sensuousness" (Said, 2003, p. 72).

However the exotic "other" personified by the Orient, as an imagined geography also became a rich source of fascination to the French post- impressionist artists. Foster (2011) argues that both impressionists and the post-impressionists turned to this tropical inspiration for tactical measures to differentiate their work. Within the circles of the painting milieu they tried to break with tradition, that saw an imaginary tropics as "space-time maps onto which psychological ambivalence and political ambition could be projected" (Foster, 2011, p. 66). This imagined exotic produced in Rousseau another level of imaginative paradise, where the "other" is depicted as a vision of utopia, painted entirely without any actual physical experience of the reality of the geography, as Rousseau collected all his tropical paradisiacal references within Paris.

The paintings' of Henri Rousseau beautifully imagine a tropical reality garnered from visits to the botanical gardens in Paris, perusing illustrated books as well as considering a taxidermy tableaux. His influence was to inspire thinkers as well as artists in terms of understanding the real and imaginary confines of geographical space. Of his visits to the Jardin des Plantes in Paris, Rousseau said, "When I go into the glass houses and I see the strange plants of exotic lands, it seems to me that I enter into a dream" (Larson, 2009, p. 196). Even in Gauguin's fascination with Tahiti we see this Orientalism played out as an authentic tropical experience where Gauguin was connected to Tahitian people through his deep involvement with them. His involvement provides insight and helps us understand the contradictions of the western projection through his depictions of people, place and culture. Never the less his work shows how he worked through and away from Orientalism. The Orientalist presumption was overcome by his authentic engagement with the people he painted and the commentary featured in his work. 
Matisse, Gauguin and Rousseau whose tropical paintings harness depictions of tropical environments as well as dealing with the fact of intense colour, highlight the necessary friction for clarifying what it was then that was imperative in making creative shifts and changes. In the case of Gauguin the catalyst for his creative shift came by travelling to the Pacific Island of Tahiti. The relationship Gauguin had with Tahiti was fraught with colonial exploitation of the native Polynesian beliefs and culture, rendered it impossible to accept the heroism that his career epitomizes (Thomson, 2004). Yet his ability to reach out and immerse himself within the fabric of the place infused his work with vigour and colour, from a global perspective which was an awakening goal of the twentieth century (Thomson, 2004). The journey that Matisse made to Tahiti is regarded as less "exemplary of the European imaginary of the exotic" (Turner, 1995, p. 71) however the impact of the tropical experience on Matisse and his work was profound. The first encounter that Matisse had with the tropics was in Tahiti in 1930 at the age of sixty. Although Matisse found the tropics later in life, he did respond vividly to his earlier experiences in Tangiers and Morocco. In the nineteenth century artists were enabled by French colonial expansion to travel through North Africa to "document an engagement, capture the appearance of the foreign landscape or to poeticise the lifestyles of the indigenous peoples" (Benjamin, 1997, p. 72).

These frameworks provided two aesthetic possibilities, firstly to examine the colour and light of the exotic location and secondly to study human life in that space. Matisse reveals the necessity of lived experience to comprehend place when he states, "The Biskra oasis is very beautiful, but I know that one must spend several years in these countries in order to extract something new and that one cannot just take one's palette and one's system and apply it" (Benjamin, 1997, p. 74). He was referring to the problem he was having with interpreting the strong torrid light. His use of visual rhyme enables him to access decoration and similitude in the construction of modernist paintings. In responding to the Pacific imagery, his work has significantly influenced modern painting and the relationship that a western audience has had to an experience of exoticism.

This exploration of tropical paradise through case studies and a painted response produces new data reflecting on how a sample group of North Queensland painters define the tropics. These outcomes are fascinating in their variety for painting in this region. It is surprising that paintings made in North Queensland vary in aesthetic outcomes yet the survey responses showed quite similar attitudes to climate and geography, and it is not surprising that this resonated in imagery that both observed and questioned this relationship. This is demonstrated by a tropical colour palette and mode of thinking in contrast to factors that come into play in temperate climates and produces its own aesthetic responses. Gauguin, Matisse and Rousseau have contributed to stereotypical notions of the tropical and exotic with and their fascination with wild untamed worlds, and have given a premise to reinvestigate a current depiction of a real tropics through the case studies. The tropics for some of the painters agreed that North Queensland is a paradise, for others nature typifies the rawness of the real tropics that "expresses the complexities and catastrophes of concrete historical experience" (Crowther, 1993, p. 192).

Through a case study approach and a visual response in the medium of paintings, it has been possible to measure the aesthetics and notions of tropical space. This gathering of data is what Stuart Sim calls a metanarrative that pursues "technological progress stretching indefinitely into the future"'Sim, 2002, p. 11). The research produced relies on revealing attributes of the material world that use rational methodologies. Sim points out the crisis or irony implicit in Postmodernism through an inability to maintain a governing aesthetic, is 
embraced as a product or feature of the movement. This passage of "incredulity towards metanarratives" (Sim, 2002, p. 15) began in 1875 as stated by Arnold Toynbee from A Study of History (1947) at the end of the Modern Age. Characteristic of the Postmodern ethos is what Sim observes in Bernard Iddings Bell "the Postmodernist is intellectually humble and spiritually hungry" (Sim, 2002, p. 15) also evident in the relationship between aesthetics, society and place.

Fast forward to contemporary North Queensland painters and this is how they describe tropical paradise: "Paradise is an inarticulate yet iconic word for a beautiful, pristine, balmy, idyllic place of arrival or retreat" but contrary to this "for some people it has been a hell on earth" (Ian Smith, 2010). Inherent tropical qualities were described as heat and humidity, idyllic islands and tropical fruit, pristine nature or erotic escapes. For Claudine Marzik, "it is the texture and the flavour of the vegetation" (2010). The impact of geography on Australian art was reflected in their response to colours of sky, foliage and water, as well as psychological influences and climate, "The big difference I noticed was the foliage, once you start getting further north you see the rainforest" (Ray Crooke, 2010) and for Margaret Olley it was "strong light," that was, "hot and colourful" (2010).

The spiritual associations implicated in the tropics included an acceptance of the idea of mother nature and indigenous spiritual beliefs, biblical representations or alternate belief systems, "The Garden of Eden thing... was used as a backdrop to show the fallibility of mankind...indigenous spiritualism didn't come from somewhere, they were just there, through a long evolutionary process" (Ian Smith, 2010) and "it's under the curse if you know your bible" (James Baines, 2010). To understand an internal vision or reaction to the tropics the painters agreed that sensory reactions to sound, temperature, colour, smell or texture were important rather than as an intuitive response, "instinct is primary...the environment enhances the focus" (Amanda Feher, 2010) and "I was brought up in the tropics as a child and the smell of mildew and colour in the tropics were very important" (Margaret Olley, 2010) as well as, "smell was very important to me in a psychological and physical sense at the Botanic Gardens... where we come alive through our senses" (Laurine Field, 2010).

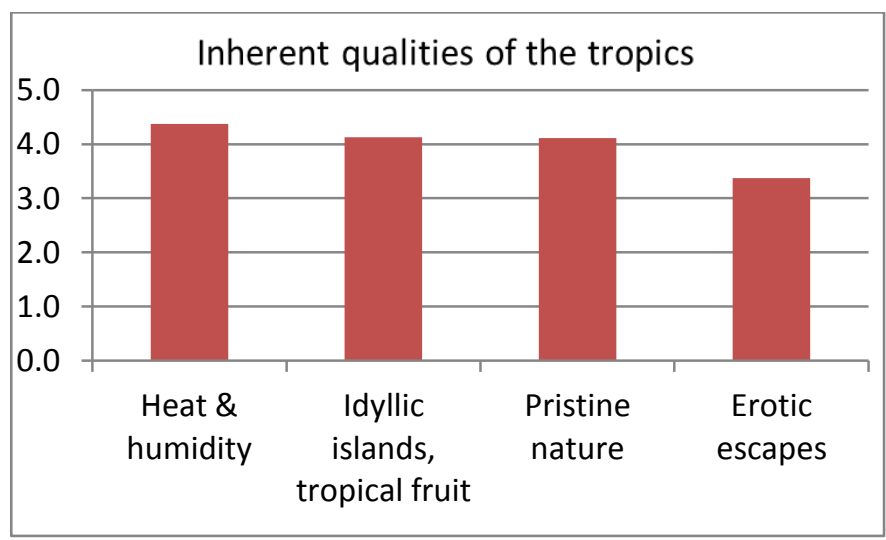

Figure 2: Survey outcomes, 2010.

Being located in the tropics means being outside the mainstream and was seen as an advantage in terms of studio practice and access to unique subject matter, but seen as a disadvantage in terms of cultural significance, "There is significance in where we are culturally with my students and studio; it contributes to the culture of here" (Claire Souter, 2010). The artists thought the special characteristic of tropical light was its brightness, yellow 
tones and clarity, "brighter greener light" (Margaret Olley, 2010) and, "The sky, the grey in the clouds...the light shining on the hill...its magic" (James Baines, 2010), however, "the tropics is prone to as much atmospheric variety as anywhere else" (Ian Smith, 2010) and "The light is very different than Europe" (Claudine Marzik, 2010).

To describe a rural tropical notion of paradise, aspects included air quality, access to nature and relaxed environment. Sometimes "there is smog from the bushfires and dust from the farming communities" otherwise "the air is clearer, the colours are clearer" (Amanda Feher, 2010). Whether or not tropical culture can participate in the mainstream was thought of positively as a souvenir or dream destination but negatively as the missing link. "Some of the meaning has come about through paintings, by artists such as Gauguin, Ray Crooke... as well as artists like Helen Wiltshire, these artists helped construct meaning" (Laurine Field, 2010) and, "The gap in Australian art or the missing chapter in Australian art is that a lot of people claim to be doing the tropics, but I don't think that they are doing the tropics properly" (Ian Smith, 2010).

The lived, perceived or intuited experiential understanding of the tropics and the imagined space of paradise is the expressed conclusion. "Aesthetic and cultural practices are peculiarly susceptible to the changing experience of space and time precisely because they entail the construction of spatial representations and artefacts out of the flow of human experience" (Harvey, 1989, p. 327). The purpose of gaining new knowledge through this research is to understand art making through theoretical and historical contexts suggested by Husserl, "To this it may be answered that the term knowledge refers to a relationship between an act of thought and fulfilling intuition" (Farber, 1943, p. 478). This creative process is rooted in an experience of Dasein, in being and time. The significance of painting is critical in expressing the inner world of a society, and the people in it, and to an extent, a barometer of the health of that society, culture, community, and most importantly acts as a catalyst for a final result of investigation as a revaluation of the seen and the unseen, the imagined and the real. This sensory response understands tropical space as "the dialectics of external and internal space, physical and spiritual, material and mental, unconscious and conscious priorities concerning the senses as well as their relative roles and interactions" (Pallasmaa, 2012, p. 19).

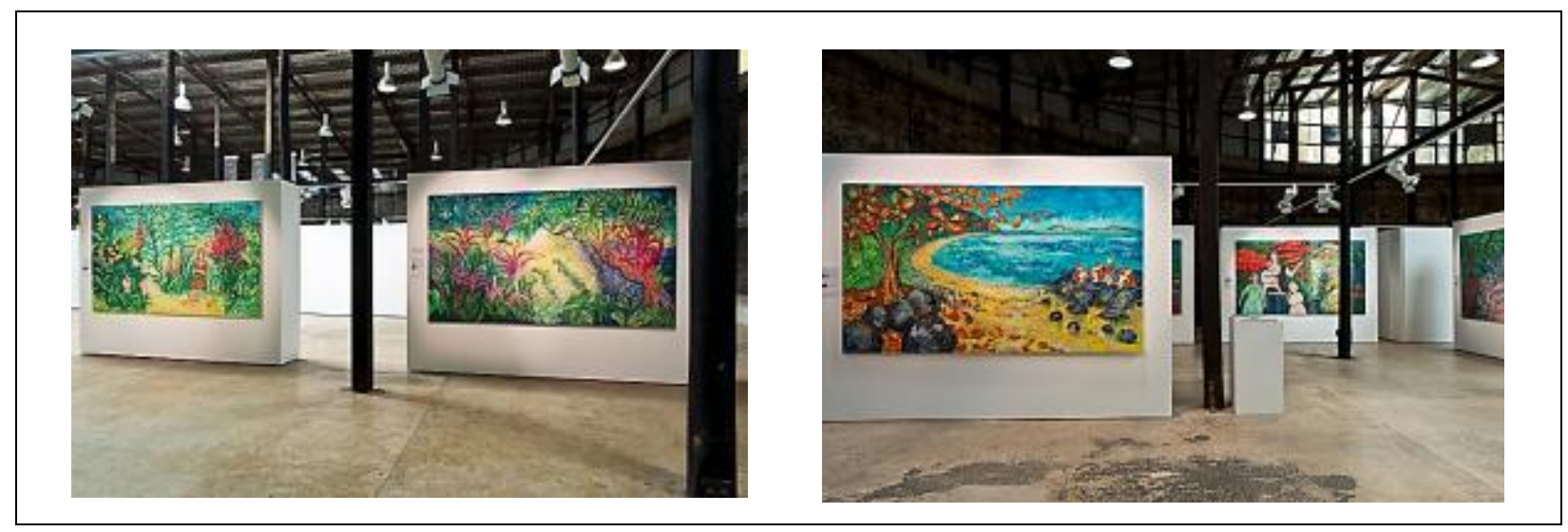




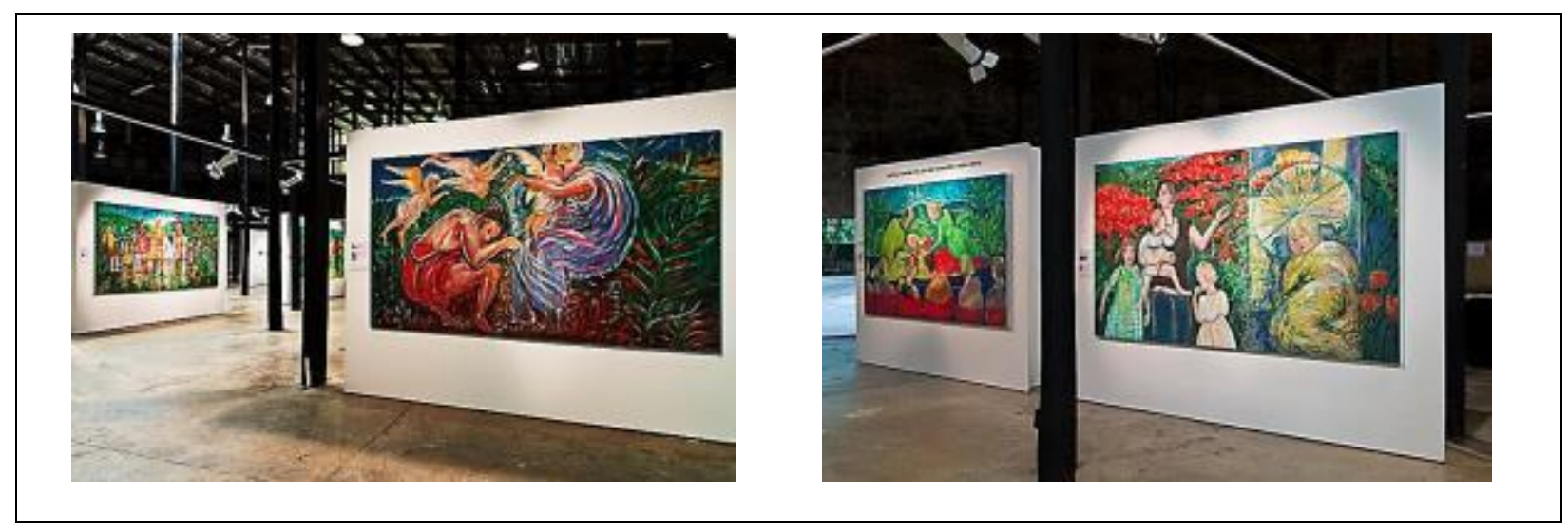

Figure 3: Tropical paradise: its light and its shadows, Tanks Art Centre, 2012.

Tropical paradise may be a dream or a construction of attitudes that illuminate Dasein, and in this investigation a real world measured response and continued question that acts as a catalyst to further enquiry. Tropical nature has been observed through historical explorations to contextualise the current day through a narrative that looks at the spirit as a projection of paradise as place. The role of painting in the wet tropics of Australia is a continuation and expansion of attitudes and ideas to depict the essence of place and the inherent qualities of lived experience of people in the tropics. This investigation has considered tropical paradise through the lenses of light and shadow. The outcome both informs my painting practice and reaches an ethnographic contribution towards lived experience in tropical space through the perceptions of painters working in the area. This has led to the understanding of perception as a subjective position "We do not see things as they are. We see them as we are" (Nin, 1961, p. 124).

\section{Works Cited}

Allen, C. 1997. Art in Australia From Colonisation to Postmodernism, London, Thames and Hudson.

Armstrong, J. 2004. The Secret Power of Beauty, London, Penguin Books.

Ashton, T. W., John 2001. The Quest for Paradise: Visions of Heaven and Eternity in the World's Myths and Religions, San Francisco, Harper Collins.

Beiser, F. C. 2009. German Idealism: The Struggle against Subjectivism, 1781-1801, Harvard University Press.

Benjamin, R. 1997. Orientalism: Delacroix to Klee. In: WALES, A. G. O. N. S. (ed.). Sydney: Art Gallery of New South Wales.

Berger-Schmitt, R. 2000. Social Cohesion as an aspect of the Quality of Societies: Concept and Measurement. EuReporting [Online], 14. Available: http://www.gesis.org/fileadmin/upload/dienstleistung/daten/soz_indikatoren/eusi/pape r14.pdf 
Cohen, L. M., Lawrence 1994. Research Methods in Education, London, Routledge.

Crowther, P. 1993. Critical Aesthetics and Postmodernism, Oxford, Clarendon Press.

Driver, F. M., Luciana 2005. Tropical Visions in an age of Empire, Chicago, The University of Chicago Press.

Farber, M. 1943. The Foundation of Phenomenology: Edmund Husserl and the Quest for a Rigorous Science of Philosophy, New York, State University of New York Press.

Foster, H. K., Rosalind \& Bois, Yve-Alain \& Buchloch, Benjamin \& Joselit, David 2011. Art Since 1900: Modernism, Antimodernism and Postmodernism, London, Thames and Hudson.

Harvey, D. 1989. The Condition of Postmodernity: An Enquiry into the Origins of Cultural Change, West Sussex, Wiley-Blackwell.

Hofstadter, A. K., Richard 1976. Philosophies of Art and Beauty, Chicago, The University of Chicago Press.

Larson, B. J. 2009. The Art of Evolution: Darwin, Darwinisms, and Visual Culture USA, Dartmouth College.

McCann, C. 1996. Critical Heidegger, London, Routledge.

Millington, J. 1987. Tropical Visions, St Lucia, University of Queensland Press.

Nin, A. 1961. Seduction of the Minotaur, Swallow Press.

Pallasmaa, J. 2012. The Eyes of the Skin: Architecture and the Senses, West Sussex, John Wiley \& Sons Ltd.

Ruskin, S. 2004. John Herschel's Cape Voyage: Private Science, Public Imagination and the Ambitions of Empire, Hants, England, Ashgate Publishing Limited.

Said, E. 2003. Orientalism, London, Penguin Books.

Searle, R. 1991. Artist in the tropics : 200 years of art in North Queensland Townsville, Perc Tucker Regional Gallery.

Sim, S. 2002. Irony and Crisis: A Critical History of Postmodern Culture, Cambridge, Icon Books.

Smith, B. 1960. European Vision and the South Pacific 1768- 1850, Oxford, Clarendon Press.

Smith, B. 1985. European Vision and the South Pacific, Melbourne, Oxford University Press.

Smith, B. 1998. Modernism's History, Sydney, UNSW Press. 
Smith, S. 1997. North of Capricorn: The Art of Ray Crooke, Townsville, Perc tucker regional Gallery.

Stepan, N. L. 2001. Picturing Tropical Nature, New York, Cornell University Press.

Thomson, B. 2004. Gauguin by Himself, London, Time Warner Books.

Turner, C. B., Roger 1995. Matisse. South Brisbane: Queensland Art Gallery.

Von Humboldt, A. 1849 Scientific Travellers 1790 - 1877: Aspects of Nature in Different Lands and Different Climates, New York, Routledge.

Wilson, G. 1998. Escape Artists: Modernists in the Tropics, Cairns Cairns Regional Gallery. 